\title{
Wisata Kuliner Sate Ikan Tanjung
}

\section{Nyoman Nugraha Ardana Putra, Sudi hardi, Yosyana Kartin, Yulia Zulfahni, Hayatus Saadiah, Raheni, Hairil Ihsan, Nurul Syahraini, Eriana, Milayati, Yuma}

\author{
Program Studi Manajemen Universitas Mataram
}

Korespondesni : nyoman.nugraha@unram.ac.id

\begin{abstract}
ABSTRAK
Desa Tanjung terletak di Kecamatan Tanjung Kabupaten Lombok Utara Propinsi Nusa Tenggara Barat. Tanjung memiliki Potensi wisata kuliner yang sangat terkenal, salah satunya yaitu sate tanjung. Sate Ikan Tanjung ini sudah sangat melekat di dalam ingatan masyarakat tanjung maupun diluar tanjung. Wisata tidak hanya berbicara mengenai keindahan alam, namun juga termasuk juga kuliner. Ketika berkunjung kesuatu daerah, hal yang tidak boleh terlewati yaitu mencicipi kuliner khas daerah tersebut. Perlu pemahaman bagi wisatawan untuk mengetahui makanan khas daerah Tanjung, prosespembuatannya dan tentu juga akan berdampak meningkatkan pendapatan bagi usaha dagang Sate Ikan Tanjung.
\end{abstract}

Kata kunci : Desa Tanjung, sate ikan, wisata kuliner

\section{PENDAHULUAN}

Wisata kuliner merupakan salah salah satu jenis wisata yangmemiliki dampak dalam perkembangan suatu daerah.Wisata kuliner jugaberperan dalam menciptakan lapangan pekerjaan dan mengurangi pengangguran serta menciptakan kesejahteraan masyarakat.Nilai positif yang dapat diperoleh dari wisata yang satu ini adalah menumbuh kembangkan makanan asli daerah yang sudah mulai tergeseroleh produk produk asing seperti pizza, spaghetti, masakan jepang danmasakan luar lainya. Wisata kuliner, boleh menjadi salah satu daya pikat tersendiri, disetiap daerah masing-masing diseluruh Indonesia. Di Indonesia sendiri wisata kuliner berkembang sangat pesat, hal ini dapat menjadi sebuah peluang bagi orang-orang untuk membuka usaha di bidang kuliner, dari dampak yang di timbulkan, tentu kita sepakat bahwa dalam pengembangan ke depan mampu menggerakan perekonomian lokal, dan juga dapat membuka lapangan pekerjaan bagi orang-orang yang membutuhkannya. Hal ini dapat mengurangi tingkat pengangguran dan kriminalitas di masyarakat.

Tanjung merupakan salah satu daerah yang memiliki potensi wisata kuliner yang sangat terkenal, contohnya saja yaitu sate tanjung. Dimana sate tanjung sudah sangat melekat didalam ingatan masyarakat. Selain sate tanjung terdapat beberapa kuliner yang terdapat di tanjung. Bahwasanya wisata tidak hanya berbicara mengenai keindahan alam melainkan kuliner. Sehingga ketika berkunjung kesuatu daerah hal yang tidak boleh terlewati yaitu mencicipi kuliner khas daerah tersebut. Agar masyarakat mengetahui makanan khas daerah tanjung maka diperlukan pengetahuan mengenai apa saja makanan-makanan khas daerah tanjung. 


\section{Waktu dan Tempat}

\section{METODE PELAKSANAAN}

Kegiatan ini di dahului oleh interview di Dusun Kandang Kaoq, Karang Pande dan Karang Bayan Desa Tanjung Kecamatan Tanjung dengan mendatangi produsen dan penjual sate tanjung. Sebagai pelopor pembuat dan pedagang atau UMKM di desa tanjung kecamatan tanjung Kabupaten Lombok Utara. ketiga UMKM ini direkomendasikan oleh pihak desa sebagai rujukan pengusaha Sate Tanjung yang suskses memperkenalkan kuliner ini secara nasional maupun internasional.

\section{Alat dan Bahan Sate Tanjung}

Alat

Tusuk sate, Blender, Panggangan, Daunpisang, Arang, Kipas sate, Wadah sate

\section{Bahan}

1 ekor ikan segar, Santan kental, 7 biji cabai merah besar 10 biji cabai kecil, 1 Bungkul bawang putih ukuran telur, 1 Sejumput terasi , $5 \mathrm{~cm}$ kunyit, $3 \mathrm{~cm}$ lengkuas, $2 \mathrm{~cm}$ jahe, 6 butirkemiri, 1 cm kencur, Garam secukupnya Gula Pasir secukupnya.

\section{Prosedur kerja pembuatan sate tanjung}

1) Ikan dipotong menjadi $3 / 4$ bagian, selanjutnya di iris sebesar jari kelingking dan sisihkan, 2) $1 / 4$ ikan di blender bersama bumbu dan santan sampai titik kekentalan yang merata. 3) Tuang hasil blender tersebut kedalam ikan yang sudah di iris, di aduk hingga merata menggunakan tangan atau sendok besar dan di diamkan beberapa saat. 4) Adonan yang telah tercampur di tusuk kemudian dibalur dengan sedikit adonan sampai merata. 5) Bakar sate yang sudah siap selama kurang lebih 5 menit. 6) Sate Ikan Tanjung siap dihidangkan.

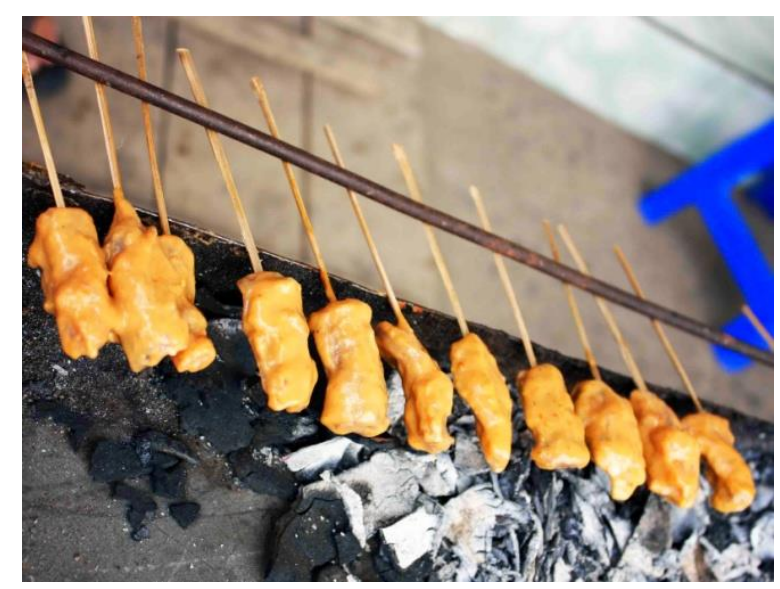

Gambar 1. Proses pembakaran sate Tanjung

\section{Hasil dan Pembahasan}

Sate ikan tanjung merupakan salah satu kuliner yang ada di lombok utara. Sate ikan tanjung ini merupakan potensi yang dimiliki oleh masyarakat desa tanjung. Keberadaan kuliner pedas nan gurih ini sangat mudah di jumpai sepanjang jalan setelah Jembatan Sokong menuju pusat kota lombok utara biasanya biasanya para pedagang mulai beroperasi dari pukul 14 : 00 wita Hingga Pukul 21 : 00 wita. 
Sate ikan tanjung ini di buat dengan menafaatkan pelantaran kios kios di pinggir sepanjang jalan tanjung, mereka berjualan hanya berlalang beberapa langkah saja. Hal ini membuat para penjual sate ikan sangat mudah di temukan oleh para pembeli.

Ikan yang di pergunakan untuk membuat sate ikan tanjung ini adalah ikan paso, ikan paso ini bnyak kita temui di pasar tanjung jenis ikan ini menjadi mahal sebagai alternafit ada beberapa pedagang yang menggunakan ikan cakalang yang cita rasanya tidak jauh beda dengan ikan paso. Bahan bahan dan alat untuk pembuatan sate ikan tanjung sangat mudah di temui untuk bahannya sate ikan tanjung itu di perlukan, 1 ekor ikan segar, santan kental, cabai merah besar, cabai merah kecil, bawang putih kunyit, lengkuas, jahe, kemiri, kencur, terasi gula dan garam. Dan untuk alatnya seperti tusuk sate, blender, panggangan, daun pisang, arang, kipas untk engipas ate yg di bakar, dan wadah tempat menaruh sate yang sudah matang.

Untuk proses pembuatan sate ikan tanjung ini relatif mudah pertama tapa ikan di potong menjadi $3 / 4$ bagian, selanjutnya di iris sebesar jari kelingking dan di sisihkan. Kedua 1/4 ika di sisihkan untuk di blender bersamaan dengan bumbu yang sudah di haluskan dan di campur dengan santan sampai titik kekentalan yang merata.

Ke tiga tuang hasil blender tersebut ke dalam ikan yang sudah di iris, selanjutnya di aduk hingga merata menggunakan tangan atau sendok besar di diamkan selama beberapa menit agar bumbu meresap.

Ke empat adonan ikan yang telah di campur tadi ditusuk menggunakan tusukan sate, kemudian di balur dengan bumbu yang sudah di campur ke dalam potongan ikan tadi sampai merata

Kelima setelah di tusuk sate kemudian di bakar selama kurang lebih 5 menit, terakhir sate ikan tanjung di hidangkan.

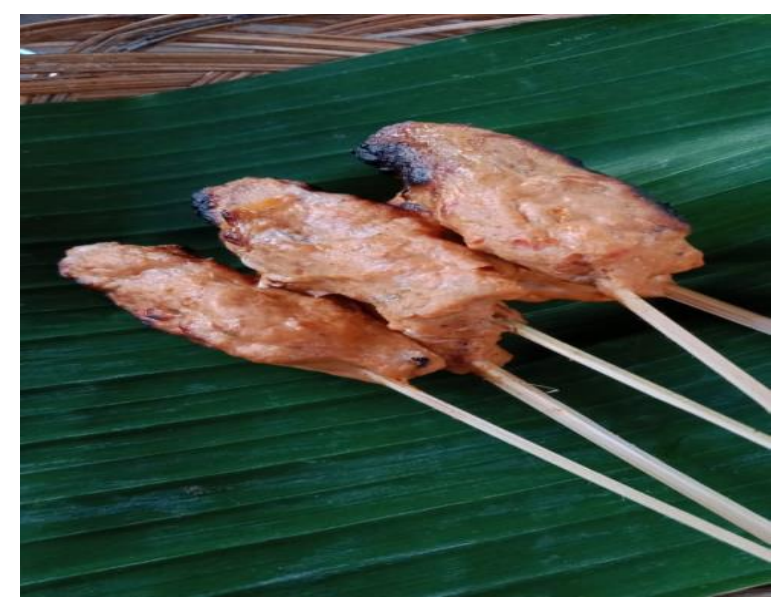

Gambar 2 . Sate tanjung telah matang

\section{Wisata Kuliner dan Pendapatan}

Saat ini Nusa Tenggara Barat (NTB) sedang berupaya untuk menggalakan pengembangan pariwisata. Salah satu komitmen pemerintah tersebut dengan menjadikan Mandalika sebagai super priority destination. Upaya tersebut tentunya harus didukung dengan mengembangkan sub sector pendukung pariwisata, salah satunya adalah Wisata Kuliner. Terlebih NTB telah terpilih sebagai destinasi wisata halal. Terkait dengan wisata halal, Desa Sembalun kembali terpilih sebagai destinasi bulan madu halal terbaik atau World's Best Halal Honeymoon 
Destination tahun 2016, Novotel Lombok Resort \& Villas sebagai resor halal tepi pantai terbaik atau World's Best Halal Beach Resort (Putra dkk., 2018).

Sebagai destinasi wisata halal sudah selayaknya wisata kuliner juga berbasis wisata halal. Hal tersebut merupakan keunggulan Pulau Lombok yang dijuluki Pulau Seribu Masjid. Keunggulan itu akan mengangkat kuliner yang berasal dari Pulau Lombok yang memiliki cita rasa tinggi dan dijamin kehalalannya. Kondisi saat ini juga menggambarkan wisatawan yang berkunjung ke Lombok adalah wisatawan domestik yang mayoritas beragama Islam. Jadi mutlak diperlukan pengembangan wisata kuliner yang mengutamakan kehalalannya.

Terlebih juga sejak 2015 silam pemerintah pusat telah mencanangkan pembangunan dari pinggiran dengan program dana desa. Melalui dana desa segala potensi yang ada di desa dapat diekplor dengan diawali pengembangan strategi desa (Putra dkk., 2019) Penyusunan dapat dilakukan dengan identifikasi bukan hanya potensi dan keunggulan saja, namun juga kelemahan dan ancamannya, sehingga keputusan yang diambil adalah keputusan terbaik dalam upaya pengembangan desa tersebut.

\section{KESIMPULAN}

1. Sate Ikan Tanjung adalah kuliner andalan desa Tanjung yang sudah lama menjadi ikon desa Tanjung Kecamatan Tanjung, Kabupaten Lombok Utara. Makanan tradisional desa Tanjung ini sudah tersohor secara nasional maupun internasional karena cita rasanya khas. Proses Pembuatan Sate ini relative mudah karena menggunakan baha-bahan yang mudah dijangkau dan mudah proses pembuatannya.

2. Adanya wisata kuliner sate ikan tanjung di desa tanjung, di harapkan mampu meningkatkan perekonomian masyarakat khususnya di bidang wisata kuliner. Adanya wisata kuliner sate ikan tanjung juga bertujuan untuk melestarikan kuliner yang sudah menjadi ciri khas masyarakat Desa Tanjung. Pengembangan wisata kuliner Sate Tanjung juga sesuai dengan capaian Lombok sebagai destinasi halal.

\section{DAFTAR PUSTAKA}

Basroni Dan Siti Juariyah. 2010. Analisis Kondisi Sosial Ekonomi Dan Tingkat Pendidikan Masyarakat Desa Srigading, Kecamatan Labuhan Maringgai, Kabupaten Lampung Timur. Jurnal Ekonomi Dan Pendidikan Volume 7 Nomor 1.

Putra, I.N.N.A, Sakti, D.P.B, Nurmayanti, S., Bisma, I.D.G, Setiawati, B.N., 2018, Pengembangan Desa Ekowisata Melalui Penerapan Hospitality Management Pada Pemilik Usaha Jasa di Sembalun. Prosiding PKM-CSR, Vol. 1.

Putra, I.N.N.A, Manan, A., Martiningsih, R.S.P., 2019, Mengukur Kinerja BUMDesa, Pusat Data Dan Informasi, Badan Penelitian dan Pengembangan, Pendidikan dan Pelatihan, dan Informasi Kementerian Desa, Pembangunan Daerah Tertinggal dan Transmigrasi, 